\title{
STRAIN RATE INFLUENCE ON FRACTURE TOUGHNESS DETERMINED BY SMALL SAMPLES
}

\author{
Pavel KONOPÍK, Martin RUND, Eva CHVOSTOVÁ \\ COMTES FHT a.s., Dobrany, Czech Republic, EU \\ pavel.konopik@comtesfht.cz
}

https://doi.org/10.37904/metal.2019.717

\begin{abstract}
This paper describes a methodology of small sample test technique for fracture toughness determination in the upper shelf region. The effect of size and strain rate has been investigated and described. Standard and small sized samples for 3-point bend test were produced and tested from several steels. The results are promising for further usage in many fields, where only limited amount of material is available, like residual life assessment, additive manufacturing industry, local properties determination in case of heterogenic material, etc. In addition, competitive methods like small punch test will be discussed as well.
\end{abstract}

Keywords: Fracture toughness, miniaturized samples, Micro-Tensile Test, Digital Image Correlation (DIC)

\section{INTRODUCTION}

Determination of mechanical properties with the use of sub-sized specimens is a topic of high interest nowadays. The application of the sub-sized samples is quite wide for all cases where only limited amount of the experimental material is available such as evaluation of additively manufactured products properties, residual life of in-service components, properties determination of developed nanostructured materials, assessment of dilatometric samples used for thermal and thermo-mechanical treatment development, local properties of components, weld joints and so on.

A number of techniques have been developed to extract mechanical properties from sub-sized specimens [1-4]. These include specimens that are either miniaturized versions of their full-scale counterparts or specifically designed discs or coupon specimens of small dimensions. One of the most used methods is the Small Punch Test (SPT). SPT is widely used, but its application is traditionally bound with necessity of known correlation parameters valid for a specific material only and thus it is impossible to use it on a blind material [5]. Recently, there are assumptions to used trained neural networks for SPT evaluation [6] but again, neural networks can be trained for some material group but they are not generally valid. Therefore, development of small size specimen techniques using miniaturized standard size samples is important, because these tests maintain very important advantage - the same loading mode as standard test samples [7]. Using advantage of application of the newest measurement equipment and techniques, miniaturized samples can be successfully used providing much more reliable data than presently used methods using correlation approach. Furthermore, such a data can be used as an input data influence on FEM simulation [8], identification of ductile damage parameters [9] or characterization of material after thixoforming [10].

The aim of this work is to contribute to global knowledge in the field of miniaturized specimen with special focus on fracture toughness and strain rate influence. Therefore, the current work is dealing with fracture toughness employing master curve and J-R curve approaches for fracture toughness parameters determination with the use mini specimens.

\section{EXPERIMENTAL MATERIAL}

As the experimental material, two structural steels were chosen - namely 34CrNiMo6 and 27NiCrMoV 15-6. Both are currently used for production of several parts in energy industry like steam turbine parts and others 
highly stressed machine parts. Such above mentioned components in service can be degraded by stresses and temperature; therefore, the prediction of their remained life is critical. The chemical composition is summarized in Table 1.

Table 1 Chemical composition of investigated materials (wt.\%)

\begin{tabular}{|c|c|c|c|c|c|c|c|c|c|}
\hline Material & $\mathbf{C}$ & Mn & Si & Cr & Ni & Mo & P & S & V \\
\hline 27NiCrMoV & 0.27 & 0.28 & 0.14 & 1.5 & 3.7 & 0.35 & 0.01 & 0.01 & 0.1 \\
\hline 34CrNoMo6 & 0.36 & 0.75 & 0.22 & 1.55 & 1.67 & 0.25 & 0.01 & 0.01 & - \\
\hline
\end{tabular}

\section{TENSILE TEST}

To prepare for testing from small volume of material, the recently-developed miniature-tensile test (M-TT) technique was chosen. M-TT specimen was suggested based on material volume requirement of specimen used for small punch test testing technique. The first suggested M-TT geometry was based on SPT specimen to prove that tensile test is possible to perform with the same amount of experimental material. FEM simulation confirmed the same loading and other condition as in the case of standard tensile test (see Figure 1).
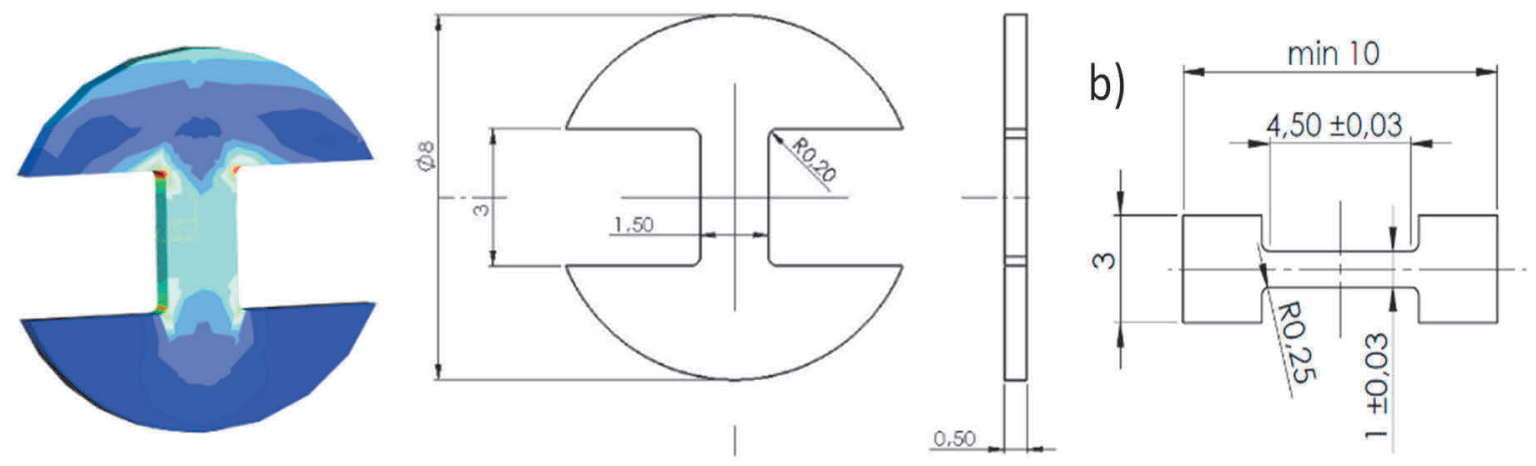

Figure 1 FEM simulation of M-TT specimen (right), M-TT initial geometry (middle), modified geometry (left)

In the case of this M-TT initial sample geometry, a shorter gauge length is used and thus elongation cannot be evaluated in the standard way. The elongation is evaluated with the use of following formula (1):

$$
A_{x}=\frac{U A_{m} * L 0_{x}+\left(A_{m}-A g U A_{m}\right) * L 0_{m}}{L 0_{x}}
$$

Where index $m$ means gauge length used for the test evaluation and $x$ is gauge length into which results are being converted.

M-TT is carried out using a special test device with high load cell sensitivity. Its linear motor runs smoothly at very slow speeds to fulfil all criteria given by the standard. The test piece is clamped in special flat grips which have been developed for this purpose. The axial extension is captured with a high-speed CCD camera integrated into the systems Mercury RT or ARAMIS ${ }^{\mathrm{TM}}$ that relies on digital image correlation (DIC), see Figure 2. As the force and extension data are captured accurately, the record need not be specially processed and the evaluation can follow the standard procedure.

Tensile tests were performed and evaluated based on ISO 6892-1 standard. The obtained engineering stressstrain record is depicted in Figure 3. Results of values from three tests for each material are shown in Table. 2, where $R_{p 0,2}$ is Yield strength, $R_{m}$ is Ultimate tensile strength, $A_{g}$ is plastic extension at maximum force, $A_{5}$ is permanent elongation of the gauge length after fracture and $Z$ is maximum change in crosssectional area. 

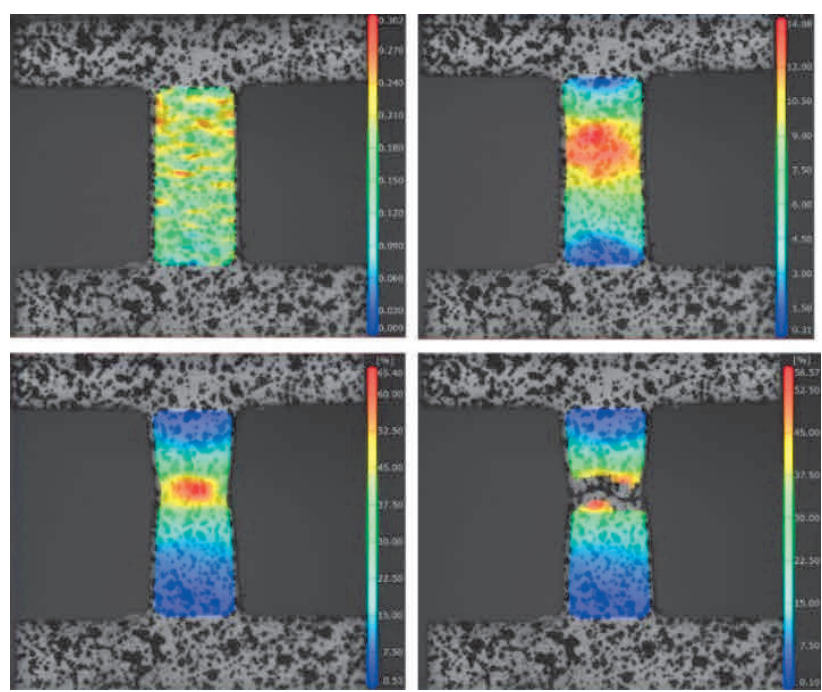

Figure 2 Example of strain measurement at different stages of tensile test for M-TT

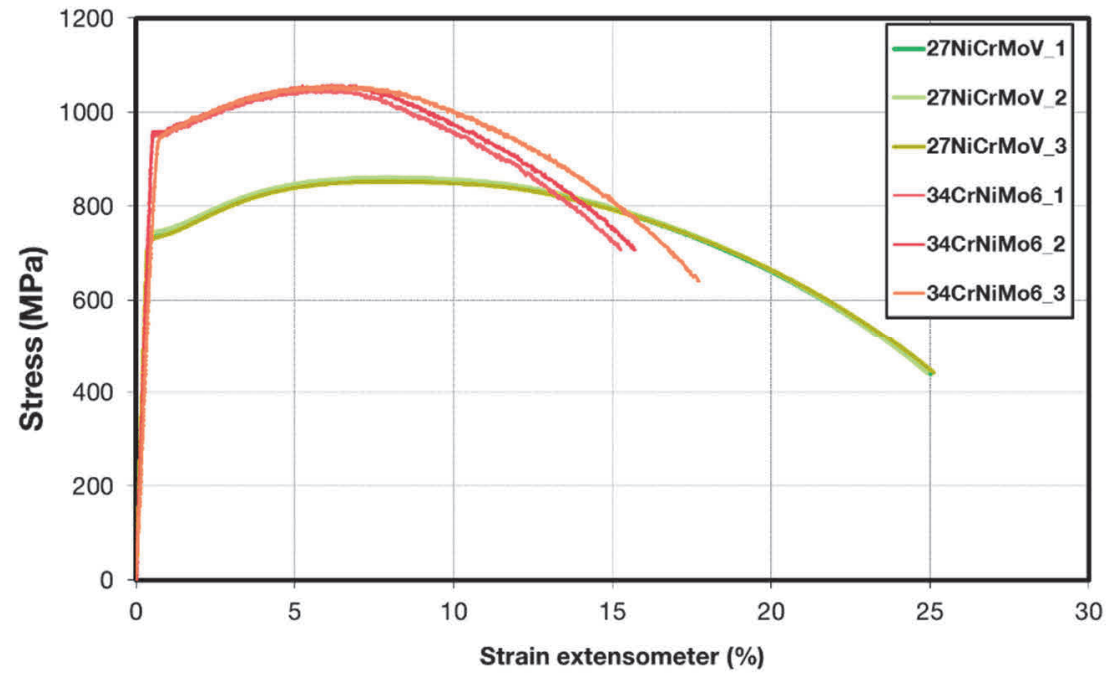

Figure 3 Tensile test records

Table 2 Results of tensile tests

\begin{tabular}{|c|c|c|c|c|c|}
\hline Specimen & Rp0,2 & Rm & Ag & A5 & Z \\
\hline & MPa & MPa & \% & \% & \% \\
\hline 27NiCrMoV_1 & 739.0 & 858.8 & 7.3 & 22.2 & 75.1 \\
\hline 27NiCrMoV_2 & 744.7 & 860.7 & 7.6 & 21.8 & 75.5 \\
\hline 27NiCrMoV_3 & 732.0 & 852.8 & 7.4 & 22.0 & 74.6 \\
\hline 34CrNiMo6_1 & 950.3 & 1047.8 & 5.9 & 15.3 & 59.5 \\
\hline 34CrNiMo6_2 & 954.9 & 1058.8 & 5.6 & 16.0 & 60.4 \\
\hline 34CrNiMo6_3 & 951.8 & 1054.7 & 6.2 & 18.4 & 63.0 \\
\hline
\end{tabular}

\section{RESULTS}

The investigated materials exhibit fully upper shelf behavior at considered testing temperature, room temperature. Therefore J-R curve concept was applied for the fracture behavior assessment. The tests and 
evaluation were carried out according to ASTM 1820. Multiple specimen testing method was applied. Samples used were three point bend (3PB, see Figure 4) samples for both materials 34CrNiMo6 and material $27 \mathrm{NiCrMoV} 15-6$. Specimens were V-notched at first and then fatigue pre-cracked up to crack length to specimen height ration of about 0,5W. Pre-cracking was performed with the use of magneto-resonant machine. Pre-cracking parameters were defined so that at the end of pre-cracking stress intensity factor $\mathrm{K}$ was kept below $20 \mathrm{MPa} \cdot \mathrm{m}^{1 / 2}$ in order to assure sharp crack tip. After samples pre-cracking, the samples were sidegrooved by $20 \%$. Testing was performed on servo-hydraulic testing system MTS 810 for quasi-static condition and using Charpy pendulum for dynamic condition. Sample deflection was measured by a clip on gauge extensometer. After test execution samples were heat tinted and the initial crack length and stable crack extension was measured. The crack lengths were evaluated on the basis of crack area measurements performed with digital image processing software. The obtained J-R curves are depicted in Figures 5 - 6.
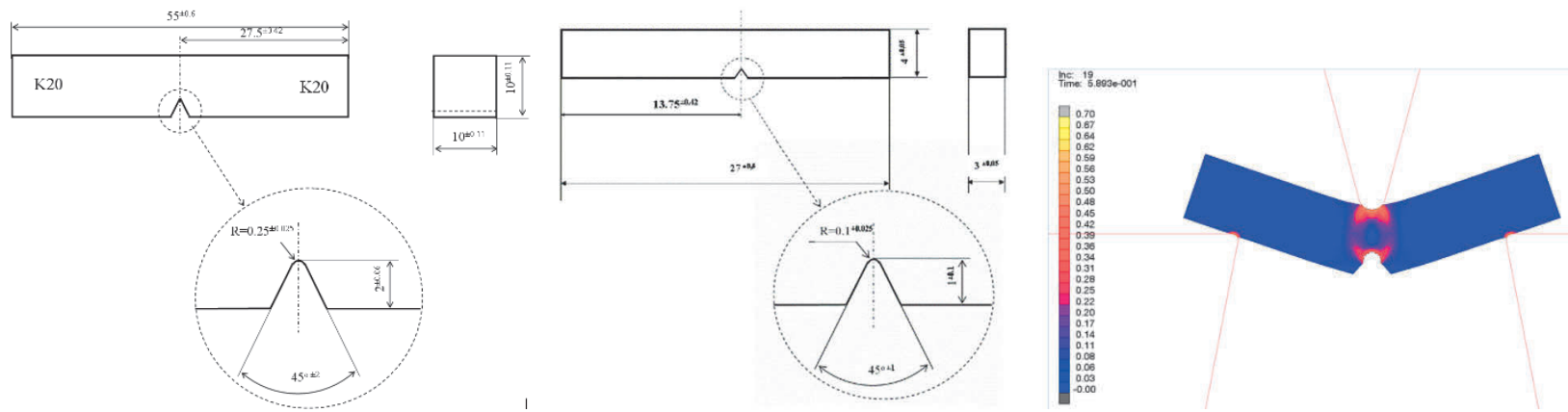

Figure 4 Charpy specimen geometry; $10 \mathrm{~mm} \times 10 \mathrm{~mm} \times 55 \mathrm{~mm}$ (left), $3 \mathrm{~mm} \times 4 \mathrm{~mm} \times 27 \mathrm{~mm}$ (middle), scheme of loading (right)
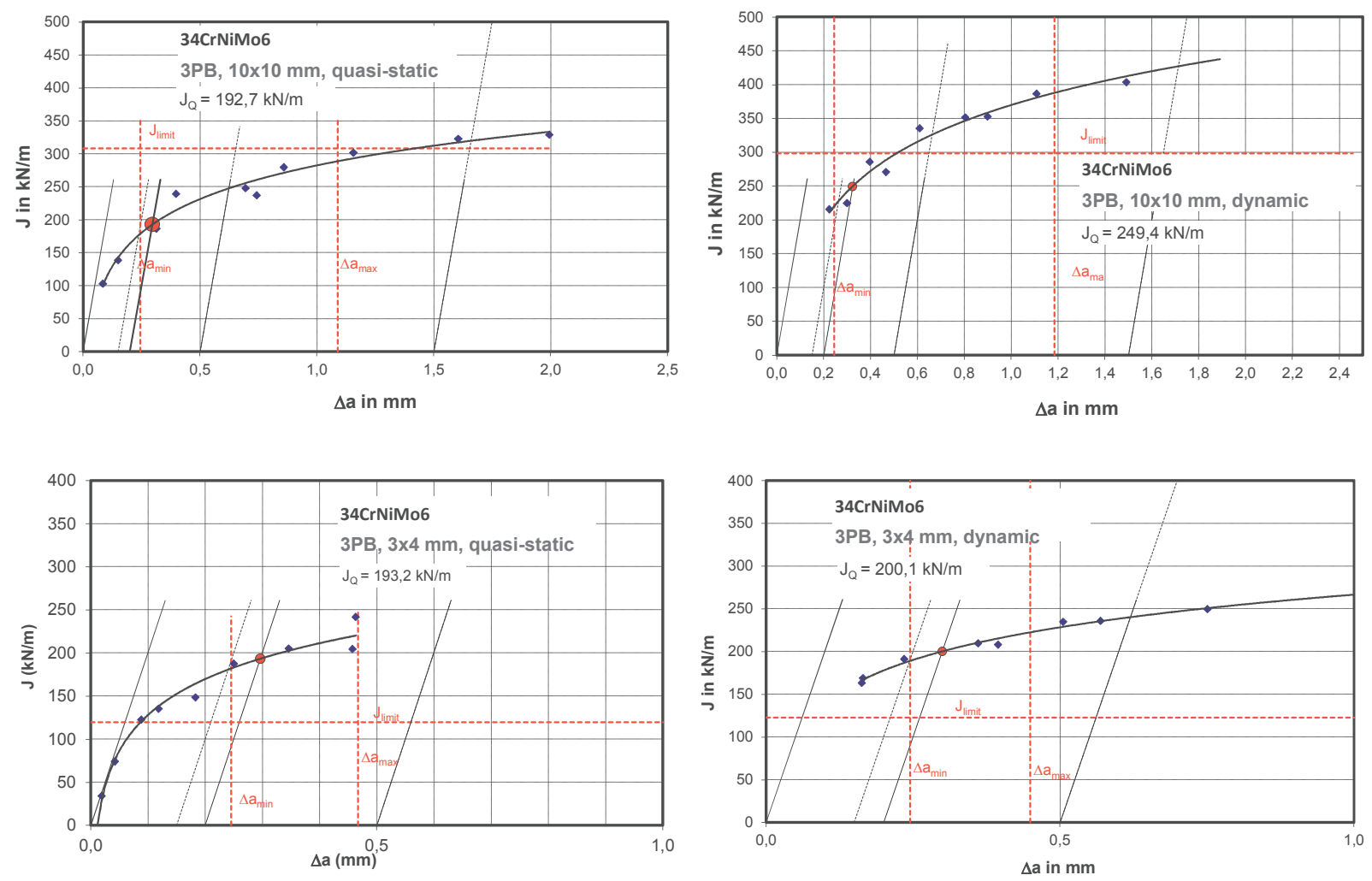

Figure 5 J-R curves; material 34CrNiMo6 

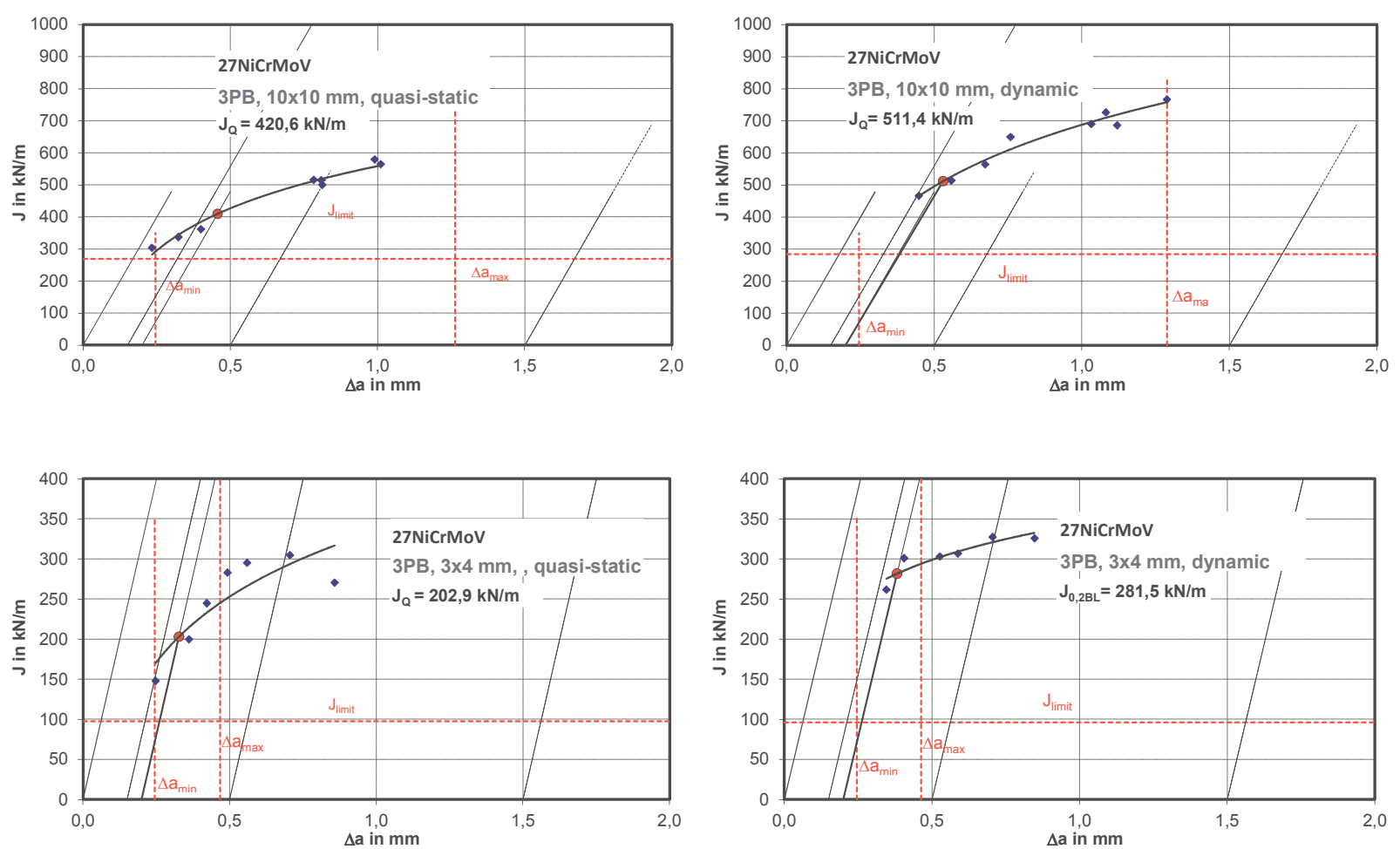

Figure $6 \mathrm{~J}-\mathrm{R}$ curves; material 27NiCrMoV

\section{RESULT DISCUSSION}

Tensile test performed on both investigated materials show very homogenous results which is necessary for further investigation of size factor in case of fracture toughness. The result of fracture toughness summarized and depicted in Figure 7 do not show clear trend for both materials. While the results for 27NiCrMoV 15-6 steel shows clear dependency of fracture toughness $J_{Q}$ on specimen dimension and strain rate, the result for $34 \mathrm{CrNiMo6}$ steel shows significantly JQ increasing only for dynamic loading of 10x10 specimen. This can be caused by higher tensile strength and less elongation of $34 \mathrm{CrNiMo6}$ steel which may cause less plastic deformation on the tip of sharp fatigue crack and therefore, the crack resistance for material with higher strength is less.

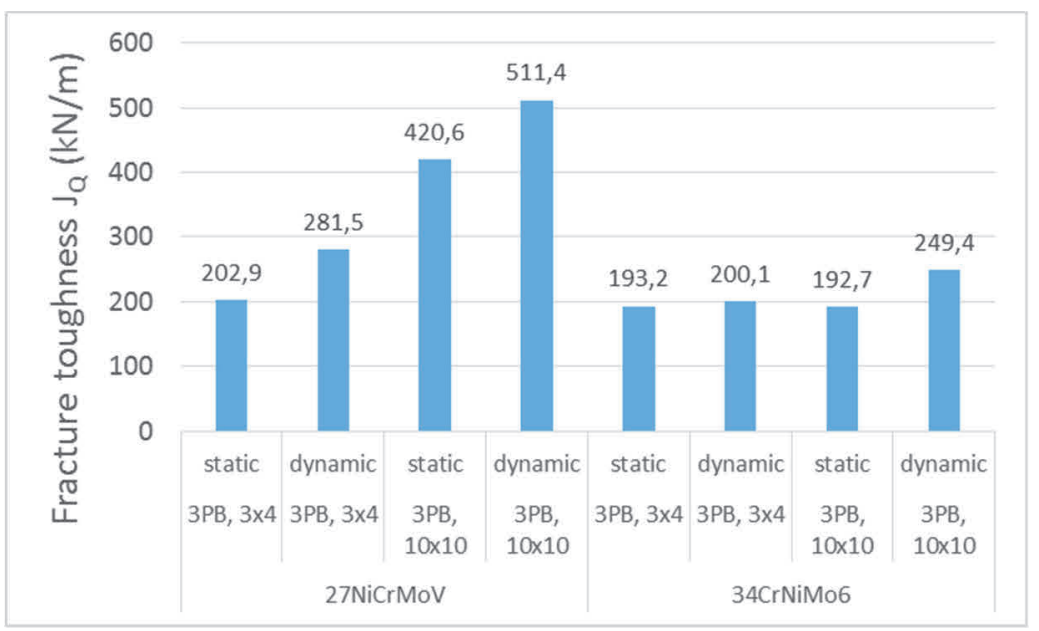

Figure 7 Fracture toughness results - graphical representation 


\section{CONCLUSION}

Tensile test and fracture toughness tests were performed using standard and miniaturized Charpy specimens. The investigated materials were two steels used for production of several parts in energy industry - namely $34 \mathrm{CrNiMo} 6$ and $27 \mathrm{NiCrMoV} 15-6$. The results indicates that fracture toughness do not depend only specimens size and strain rate but on other mechanical characteristics as well. The data contribute to global knowledge in this field. Further investigations with additional materials and specimen geometries are planned to provide sound base for the methods applicability for the currently investigated materials.

\section{ACKNOWLEDGEMENTS}

\section{This paper was created by project OP VVV COMEX registered under number CZ02.1.01/0.0/0.0/16_019/0000836, Research of advanced steels with unique properties.}

\section{REFERENCES}

[1] LUCAS, G.E. and ODETTE, G.R. The role of small specimen test technology in fusion materials development. J. Nucl. Mater. 2007. vol. 367-370, pp. 1549-1556.

[2] YUAN, J. and ZHANG, Z.L. Influence of specimen thickness with rectangular cross-section on the tensile properties of structural steels. Mat. Sci Eng. A- Struct. 2012. vol. 532, pp. 601-605.

[3] OLBRICHT, J.; BISMARCK, M. and SKROTZKI, B. Characterization of the creep properties of heat resistant 9$12 \%$ chromium steels by miniature specimen testing. Mat. Sci. Eng. A - Struct. 2013. vol. 585, pp. 335-342.

[4] CAO, L. and BÜRGER, D. Testing of Ni-base superalloy single crystals with circular notched miniature tensile creep (CNMTC) specimens. Mat. Sci. Eng. A-Struct. 2018. vol. 712, pp. 223-231.

[5] DZUGAN, J. and KONOPIK, P. Determination of local tensile and fatigue properties with the use of sub-sized specimens. In ASME PRESSURE VESSELS AND PIPING CONFERENCE 2015: New York: Amer. Soc. Mechanical Engineering, 2015, pp. 459- 464.

[6] ABENDROTH, M. and KUNA, M. Determination of deformation and failure properties of ductile materials by means of the small punch test and neural networks. Comp. Mater. Sci. 2003. vol. 28, pp. 633-644.

[7] BRYNK, T., MOLAK, R.M., PAKIELA, Z. and KURZYDLOWSKI, K.J. Mini-samples technique in tensile and fracture toughness tests of nano-structured materials. Materials Challenges and Testing for Supply of Energy and Resources. 2012. pp 221-234.

[8] DZUGAN, J. and ZEMKO, M. Input data influence on FEM simulation of steam turbine blades materials hot forming, Advances in Materials and Processing Technologies XV. Materials Science Forum. 2014. vol. 773-774, pp. 79-88.

[9] DZUGAN, J., SPANIEL, M. and PRANTL, A. Identification of ductile damage parameters for pressure vessel steel, Nuclear Engineering and Design. 2018. vol. 328, pp. 372-380.

[10] JIRKOVÁ, J. and RUBEŠOVÁ, K. Effect of the Parameters of Semi-Solid Processing on the Elimination of SharpEdged Primary Chromium Carbides from Tool Steel. Metals - Open Access Metallurgy Journal. 2018. vol. 8, no. 9, pp. 713-718.

[11] DZUGAN, J.; NOVÝ, Z. and KONOPIK, P. Improvement of Fatigue Properties of 34CrNiMo6 Steel by Controlled Thermomechanical Treatment. In METAL 2010: 19th International Metallurgical and Materials Conference, Rožnov pod Radhoštěm: TANGER, 2010, pp. 421-426. 